artigo] VOLUME 10 | NÚMERO 21 | MAIO 2017

[TAISA VIEIRA SENA]

Doutora em Comunicação e Semiótica pela Pontifícia Universidade Católica do Paraná (PUC-PR/CPS-PUC-SP).

E-mail: taisavieira13@gmail.com

\title{
Os sujeitos perfumados da publicidade: uma proposta de tipologia
}

\author{
The fragrant subject of advertising: a proposed \\ of typology
}

[^] [resumo] Este artigo apresenta um conjunto de análises de publicidade de perfume de marcas de alta-costura e prêt-á-porteridentificadas a partir de um recorte de 142 anúncios veiculados nas edições regulares da revista Vogue Brasil, do ano de 2010 a 2014. A partir das considerações aqui apresentadas, embasadas nos conceitos e definições de Eric Landowski e Ana Claudia de Oliveira, propomos uma tipologia dos sujeitos perfumados que figuram nos textos e nos discursos publicitários propagados socialmente por meio de práticas especificas.

\section{[palavras-chave}

\section{publicidade de perfume; sujeito perfumado;}

tipologia; semiótica.

[abstract] This article presents a set of analyzes of perfume advertising of haute couture and prêt-à-porter brands, identified from a cut of 142 ads published in the regular editions of Vogue Brasil from the year 2010 to 2014. From of the considerations presented here, based on the concepts and definitions of Eric Landowski and Ana Claudia de Oliveira, we propose a typology of the perfumed subjects that appear in the texts and in the advertising discourse propagated socially through specific practices.

[keywords] perfume advertising; subject fragrant; typology; semiotics. 
Os perfumes estão inseridos no universo da moda, no qual a escolha de conceitos e imagens, de elementos formais e até de seus processos produtivos é mediada pelo contexto cultural e constituirá seu discurso - orientador de determinadas práticas interativas entre os sujeitos sociais. Por sua vez, a publicidade de moda, em suas narrativas, organizará a lente através da qual o destinatário perceberá o universo criado por cada marca, decidindo, posteriormente, assumi-lo como seu ou não.

Na indústria da moda, o anúncio publicitário comunica a essência da marca e de uma coleção, utilizando-se de imagens modalizantes de sujeitos que manifestam valores, identidades e subjetividades que transitam entre os espaços vagos de sentidos e sua concretização pelos elementos da moda. Como explicam Castilho e Martins (2005, p. 28): "Nos mundos ilusórios criados pela moda, o sujeito entra em conjunção com determinados produtos aos quais são agregados valores subjetivos. São esses, por sua vez, que promovem a satisfação do sujeito em relação à sua identidade construída".

0 discurso da moda atua de forma "modal" na construção e percepção do "eu" e do "outro", sendo capaz de influenciar a identidade e o comportamento dos sujeitos, alterando seus pensamentos e modos de agir, seus modos de manifestação, isto é, a concretização desses discursos ancorados em textos sincréticos e nos significados simbólicos e semissimbólicos que os objetos projetam - o corpo, a roupa, os movimentos etc. Como os demais discursos sociais, a moda, por seus modos de conjunção que constrói junto ao corpo, "concretiza desejos e necessidades de uma época, circunscrevendo os sujeitos num determinado espaço de significação" (CASTILHO; MARTINS, 2005, p. 28).

Partindo-se do pressuposto de que o consumidor se identifica com a marca, 0 produto e as presentificações de estados de alma que o anúncio apresenta, é mister reconhecer que ele se projeta nessas identificações. As publicidades criam um universo que leva o sujeito ao desejo, à compra e ao consumo de um objeto tanto por seu valor utilitário como pelo que ele passa a significar, seu valor simbólico.

Para Ana Claudia de Oliveira (1997), a compra é um ato mediante o qual o sujeito-comprador quer poder se reconhecer, e esse ato o coloca em evidência em um percurso modalizador que transforma o estado desse sujeito quando entra em conjunção com o objeto de valor da busca. Com efeito, pelo ato da compra, o sujeito, em um estado virtualizado do querer, pela sua volição, quer e necessita desenvolver modalidades cognitivas para poder e saber como realizar a performance, isto é, a alteração de estado de disjunção para a conjunção com o objeto de sua escolha. Só quando esse sujeito de busca pode executar a ação e sabe como fazê-la, é que ele se encontra em um estágio atualizado para, em seguida, passar para o estágio de sujeito realizado, quando, por fim, executa a performance prevista, a da conjunção - e posteriormente é reconhecido e por vezes recompensado por isso (quer por ele mesmo, quer pelo outro). A complexidade das modalidades teorizadas pela semiótica em Greimas e Courtés (2011) ajuda a entender a busca de competências que o sujeito do fazer empreende para se tornar um sujeito competente para suas performances no mundo, sendo que elas lhe atribuem um lugar e um pertencimento social, assim como uma identidade no contexto de sua existência. Assim, no estudo dos percursos narrativos de busca, essas postulações serão utilizadas com certas complementações que justificaremos necessárias em função dos tipos de sujeito da ação que já tem as competências para executá-las.

No modo como a mensagem publicitária é construída, há um destinador (fabricante e/ou comerciante) cujo interesse se dá em convencer o destinatário (consumidor ou intermediário) a fazer aquilo que ele, destinador deseja, que é levar o destinatário ao ato de aquisição do produto. Logo, por meio da compra, de um produto ou de serviço, estabelece-se um contrato entre destinador e destinatário, no qual estão envolvidas qualidades como fidúcia, veridicção, afeto etc. 
Em nossa pesquisa, somos guiados pela afirmação de Landowski, na qual o semioticista diz que o perfume age "como uma força irresistivel que se apodera inteiramente do sujeito, ou como invólucro transparente que recobre o corpo e parece transfigurá-lo como o faria uma segunda pele, mais perfeita, mais sensível" (LANDOWSKI, 2002, p. 145). Munido dessa pele mais sensível, temos, então, o "ser perfumado". Os anúncios estudados no decorrer da pesquisa são textos sincréticos em que se constroem universos de sentido pautados na sedução e no desejo. Ambos os atributos são transmutados para o perfume e sua marca e, consequentemente, ao seu usuário (o enunciatário projetado nos anúncios), que recebe suas qualidades eufóricas, criando o que vamos chamar de "mítica do ser perfumado", como um modo de ser e estar no social.

Floch (1985), baseado nos estudos de Lévi-Strauss, considera o mito uma instância de mediação entre o natural e o cultural. 0 mito quer significar a construção de uma apreensão lógica do mundo, é uma informação articuladora de sentido. Floch concebe a narrativa mítica como uma operação de transformação sobre os códigos semissimbólicos; para ele o mito só pode ser explicado dentro de um sistema cultural. Dessa forma, o mito permite reorganizar conceitos por meio de procedimentos discursivos (explicados no percurso gerativo) que colocam em relação a ordem natural e cultural das coisas. Posicionado no centro do processo de significação, o mito articula a experiência sensivel dos sujeitos edificando a organização significante de uma realidade (ainda que seja uma entre tantas). Para Greimas (1976), a mitologia se vale da figuratividade para criar narrativas sobre sua própria sociedade, reiterando imagens e valores por ela euforizados. Tomando por base esses conceitos, acreditamos que a mítica do ser perfumado conduzirá a uma naturalização das construções sociais desse sujeito que se perfuma não só pela fragrância, mas principalmente pelos valores positivados pelas marcas de alta-costura e prêt-à-porter, edificados nas relações simbólicas e semissimbólicas. No que diz respeito ao discurso mítico, Landowski afirma que:

[...] não há nem circunstâncias automaticamente geradoras, nem gerações mecanicamente constituídas, mas sujeitos coletivos que alcançam a existência semiótica - aos quais advém uma "identidade" - pela construção de um certo número de figuras referencias, ou de "símbolos". [...] "Mítico" deve ser tomado aqui em sua acepção técnica precisa: trata-se, ao mesmo tempo, da produção das diferenças, sem as quais não haveria significação, e da conciliação dos termos opostos, sem a qual não haveria mais sentido. [...] o encadeamento das gerações representa, a todo instante, a superposição de um começo a um fim. Como se diz em linguística, a assunção da dimensão temporal pelo sujeito enunciante faz intervir, assim os mecanismos de aspectualização. (LANDOWSKl,1992, pp. 52-54)

A mítica do ser perfumado pode nos fornecer um caminho para compreender como se dá a apreensão da experiência sensivel de se perfumar como um modo de ser e estar no social, considerando o perfume, seus tipos, modos e situações de uso como elementos constituintes dos traços identitários do simulacro de sujeito que nos levam à tipologia dos sujeitos perfumados da publicidade de perfume.

Os perfumes fazem parte do imaginário social como algo inerente aos procedimentos de manipulação por sedução, e sabemos que, em publicidade, nada é feito sem uma finalidade que orienta as ações de um sujeito destinador sobre outro sujeito, o tornado sujeito desejante, que vai com o seu desejo passar do estado à ação, no caso, de compra, de consumo de adquirir produtos com valores de moda etc.

Podemos postular que tudo que é figurativizado em um anúncio participa da 
construção semântica e plástica conformadora da consistência sensivel do que nele é projetado e construído sensivel e inteligivelmente. As escolhas que a marca efetua e põe em articulação nos anúncios produzem no público uma disposição para sentir os sentidos instalados nos objetos semióticos, ou seja, uma disposição afetiva a partir da consistência sensivel do arranjo. Perguntamo-nos, então, como é criada nesses anúncios a consistência sensivel que toca a disposição afetiva de quem os recebe? E ainda: como são essas apreensões que estarão na base da construção da aura e dos valores do perfume e do ser perfumado? No que tange à disposição afetiva: como o anúncio consegue conferir, a partir de uma visualidade, a sensação olfativa que qualifica distintivamente cada perfume?

Dessas distinções é que pensamos ser possível fazer erigir da pesquisa realizada uma tipologia do ser perfumado que veicula simulacros e modos de presença distintivos de diferentes sujeitos no espaço de interação social. Acreditamos que as qualidades atribuídas ao produto no processo comunicacional da publicidade é que vão estruturar os seus valores para que sejam capazes de atuar como valores mitológicos que explicam a sociedade atual. Pois, o que é veiculado não são as fragrâncias, mas os valores e sentidos nelas investidos, com o propósito de conferir a identidade do perfume, a da marca e, por correlação, a identidade de quem os porta.

Para chegarmos a tal depreensão, partiremos dos estudos de uma semiótica da experiência sensivel proposta por Landowski (2005), que privilegia as ordens do cognitivo e do sensivel, dos efeitos de sentido decorrentes do contato com as qualidades estésicas imanentes às coisas ou aos seres com os quais nos confrontamos (ou com os quais nos conformamos). Os anúncios propiciam estudos além do inteligivel e, por isso, nossa investida também é sobre o sensivel, abordando as interações sujeito-sujeito como uma relação em que a simples copresença interativa dos actantes da cena enunciativa que participam do ato de ver o anúncio (e de servisto nele) já é eleita como apta a fazer sentido. Conforme Landowski:

Entram então em relação, de um lado, sujeitos dotados de "sensibilidade" - de uma aptidão para sentir e, portanto, de uma competência estésica - e, do outro, manifestações dotadas, enquanto realidades materiais, de uma consistência estésica, isto é, de qualidades ditas, elas também, "sensiveis" (especialmente de ordem plástica e dinâmica), oferecidas à nossa percepção sensorial. (LANDOWSKI, 2005, p. 3)

Temos, assim, um sujeito que julga um objeto além (e aquém) da sua inteligibilidade, projetando-se como um corpo que experimenta a presença do outro corpo. Nessa relação, o corpo desenvolve operações por meio das quais age sentindo o sentido, graças à condição estésica. Ana Claudia de Oliveira (2010) explica que a estesia é percebida como a condição de sentir as qualidades sensiveis emanadas das mais distintas manifestações, que, por sua vez, exalam a sua configuração para que tal experiência estésica seja capturada, sentida e processada, fazendo sentido para o outro.

No nosso caso, para tal depreensão da consistência estésica, a análise requerida exige que se imponha um trabalho descritivo e analítico da organização estética dos aromas corporificados nos arranjos publicitários impressos. Que recursos de linguagens são empregados para o enunciatário fazer sentir o perfume? A mensagem elaborada no anúncio publicitário está correlacionada diretamente com a construção de um modo de ser e agir, de acordo com a sociedade na qual ela ganha estampa.

Sobre o modo de interagir da publicidade nos fazendo desejar um produto, Landowski (2006), em estudos realizados sobre a publicidade de perfumes, afir- 
ma que, para a publicidade fazer a mediação e instalar o desejo pelo produto, é necessário que entre ela (o modelo) e nós - entre corpo sentido e corpo sentindo - o produto se coloque como um estranho: esta é a triade a partir da qual parte o semioticista: ela, o produto e ele (ou, no caso estudado, o feminino, o perfume e o masculino).

Assim, o perfume também tem que significar, no mesmo registro, a emoção e o desejo, funcionando como coisa mediadora entre os corpos e servindo como um traço de união entre eles. Nessa mediação, ocorre a transfiguração do objeto perfume em substituição ou efetivação da presença do outro sobre e com o corpo feminino. Por processos de metonímia, então, o perfume é uma parte do masculino com a qual o feminino se relaciona (quer como ausência sentida, presença projetada, espera, quer como presença carnal etc., como veremos no decorrer das análises).

Além disso, pelas propriedades objetais do perfume sobre as quais o feminino projeta sua subjetividade e, consequentemente, por meio delas, ele afirma sua constituição identitária como sujeito do mundo e, assim, o perfume se configura também como metáfora da indumentária, revestindo o corpo feminino, imbricando à sua pele, assim como a indumentária, uma segunda pele, que torna a primeira, nos dizeres de Landowski, "mais perfeita, mais sensível" (LANDOWSKI, 2002, p. 145).

Podemos dar um tratamento a esses procedimentos empregados como regidos pelos mecanismos narrativos do regime de junção e pelos do regime de união (LANDOWSKI, 2014). A articulação desses dois regimes permitirá que se aborde nos anúncios estudados de que maneira, por meio das paixões -com ou sem nome -, o consumidor é levado a desejar o perfume. Dessa forma, o que é consumido é muito mais os valores atribuídos ao perfume, à sua marca e, consequentemente, ao usuário, do que apenas a fragrância e os aromas nele contidos. 0 que o sujeito busca ao se perfumar com esse ou aquele perfume são simulacros projetados no anúncio com os quais ele se identifica.

Segundo Landowski (2014), quando analisamos uma narrativa com base no regime da junção, supomos que os actantes sujeitos não agem diretamente uns sobre os outros, a não ser por meio dos "objetos-valor". Nesse modo de interação, as modificações de estado que afetam os sujeitos dependem de sua conjunção ou disjunção com os objetos-valor, referindo-se, principalmente, à questão de ter ou não ter os valores. Já no regime de união trata-se da questão dos modos de ser e estar no mundo desses actantes em interação. A união é, assim, um modo de interação e de construção do sentido baseado no contágio entre os sujeitos, em que o contato direto, isto é, a copresença interativa dos actantes gera sentido e cria novos valores. Portanto, o conceito de união serviria para explicar os estados de alma e os estados somáticos dos sujeitos em interação face a face, uma copresença mútua, ou seja, para a construção do sentido em ato, apreensível em situação. Landowski explicita essas relações da seguinte maneira:

Ao lado da lógica da junção entre sujeitos e objetos, que fundamenta a abordagem dos fenômenos de interação pensados em termos de estratégias de persuasão e de fazer fazer, devemos prever uma problemática do fazer ser que ponha em jogo um outro tipo de relações entre actantes, da ordem do contato, do sentir, e em geral daquilo que chamaremos de união. Esquematicamente, enquanto é próprio do regime da junção fazer circular entre os sujeitos, objetos que têm significação e um valor já definidos, segundo o regime de união, no qual os actantes entram estesicamente em contato dinâmico, é sua co-presença interativa que será reconhecida como apta a fazer sentido, no ato, e criar valores novos. (LANDOWSKI 2005, p. 19) 
0 fazer sentir ocorre por contágio, no qual um sujeito age sobre o outro. Landowski (2005) explica que o contágio pode ser da ordem da enfermidade, quando, por exemplo, um sujeito contamina outro de forma infecciosa, ou pode ser afetivo. Essa segunda maneira, a do contágio por afetividade, é a que nos interessa, na medida em que ela se dá como partilha imediata dos afetos do corpo e da alma, implicando em uma continuidade da paixão que só poderá ser da ordem da união entre corpos sujeitos. Essa forma de contágio nos proporcionará sentir juntos o fazer do perfume. 0 contágio afetivo atua tanto no plano intersomático quanto no intersubjetivo, como um processo gerador de sentido e, por isso mesmo, suscetível de fazer nascer novas identidades, individuais ou coletivas. Tem-se a noção de um fazer junto e ao mesmo tempo, e mais: se possivel, no mesmo ritmo, seja por alinhamento unilateral de um (ou vários) dos protagonistas em relação ao outro, seja por ajustamento reciproco. De acordo com o semioticista:

\begin{abstract}
Em contrapartida, a outra forma de contágio, concebida em termos semio-estésicos, por se atualizar somente in praesentia, não teria dessas complacências. Aqui, não há mais agente patogênico autônomo e objetivável: é a própria presença de um sujeito - rindo, desejando, etc. - junto ao seu outro que faz com que o segundo, quer de bom grado quer não, se encontre comovido, transformado, contaminado pelo primeiro. (LANDOWSKI, 2005, p. 40, grifo do autor)
\end{abstract}

Sendo assim, o efeito de presença é da ordem do poder ao mesmo tempo em que é da ordem do sentido, e o sentido que se constrói por meio dela pode ser fruto de uma imposição unilateral ou de uma modelagem recíproca. 0 tipo de presença determinará então o tipo de ajustamento entre os sujeitos.

Como veremos mais adiante, a instauração do enunciatário das publicidades de perfume se dá pela construção discursiva que orienta os modos de elas dizerem o que dizem e contarem suas narratividades. Assim, os enunciatários são convocados a participar da cena enunciativa como interlocutores diretos das personagens das publicidades, que os convocam, sobretudo, pelo olhar. Desse modo, os enunciatários configuram-se como observadores ou testemunhas da cena que se apresenta diante de seus olhos. Tal convocação se dá de maneira tão intensa que é capaz de transmudar o "mero espectador" em sujeito partícipe da cena enunciativa, alterando, portanto, seu estatuto de sujeito "do ver" para sujeito do "sentir-junto" o que lhe é apresentado.

Esse movimento de mudança de posição enunciativa por meio dos recursos da textualização e da discursivização que investem as estratégias de articulação da copresença é o que faz o sujeito sentir as paixões e os afetos do outro, que são desencadeados no seu próprio corpo, inclusive alterando seu estado anímico. É, pois, o contágio, este processo de subjetivação intrínseca a determinados tipos de discursos sociais, que participa do regime de união anteriormente citado e que difere das estratégias previstas no regime de junção, cuja relação se dá entre sujeito e objeto de modo objetivante.

Para ampliar a discussão em torno dos modos de construção que os sujeitos empreendem para edificar uma forma de estar na sociedade, é necessário que se aborde o conceito de "simulacro", fundamentando-o, conforme a orientação teórica deste trabalho, na teoria semiótica.

Landowski (apud GREIMAS; COURTÉS, 1989) descreve o verbete simulacro como sinônimo de modelo que permite sublinhar o caráter referencial das construções, com a ajuda das quais, a semiótica se esforça por dar conta dos fenômenos de produção e apreensão de sentido. Em complemento, Bertrand (2003) afirma que 
a projeção de simulacros é uma característica central da enunciação passional, e consiste em uma espécie de desdobramento imaginário do discurso. A comunicação se estabelece então no plano do funcionamento discursivo: na troca passional, cada um dos interlocutores dirige seus simulacros aos simulacros do outro.

Os simulacros, além de uma função cognitiva (fazer saber e fazer querer), também desempenham um papel na edificação do sentido, construído por parceiros no agir em reciprocidade, em que cada um absorve do agir do outro uma emoção, apoiados pelos modos de sentir, ou seja, na dimensão estésica.

As sensações que os anúncios de perfume despertam nos leitores se fundam nos simulacros que remetem à identidade da marca, à posição social que a posse ou que o contato com um produto pode indicar e ao pertencimento que o sujeito passa a ter no social, assim como o seu compartilhamento. Para Ana Paula Miranda (2008), a moda é associada ao eu, aos traços de personalidade, ao jeito de vestir - em nosso caso, ao jeito de se perfumar, nos fazendo depreender o jeito de ser. A autora afirma ainda que o que os consumidores realmente querem possuir quando consomem uma marca é a admiração dos outros e a demarcação de sua personalidade com as características e os traços de caráter específicos que a marca vai transferir. Em outras palavras, tratam-se de leituras interpretativas do mundo a partir de construções de simulacros, e elas vão orientar o modo de 0 sujeito ser, transitar e estar no mundo.

Os anúncios, com suas imagens cuidadosamente produzidas, tendem a mostrar estados de alma que objetivamos qualificar. Os modelos das figuras humanas são sempre belos e situados em um mundo quase mágico, em atmosferas muitas vezes oníricas, ou de relação de poder instauradas, criando outras possibilidades de realidades aos consumidores, mediadas pela aquisição do perfume. "Mas, entre essa beleza que nos comove porque é (ou simula ser) comovida e nós, espectadores convidados a sentir o que sente aquele corpo, a publicidade instala, pois é esse o seu papel, a mediação de um terceiro: o produto a ser promovido" (LANDOWSKI, 2006, p. 18).

Por essas presenças que identificamos no conjunto de anúncios será possível, então, erigir uma tipologia dos sujeitos com seus estados de alma representados para os consumidores. Para tanto, lançaremos mão da análise do denominado "percurso gerativo do sentido", que trata de um modelo de previsibilidade (um simulacro, portanto) que orienta a produção de sentidos dos discursos.

De acordo com Ana Claudia de Oliveira (2010), nos processamentos da enunciação na produção midiática, desenvolve-se o exame das interações entre 0 enunciador e o enunciatário, que a autora chama de interações discursivas. Essas são caracterizadas pelos arranjos estéticos da expressão que nos permitiram observar os distintos regimes de presença nos enunciados de fazer ser e de fazer fazer, que mostram os discursos como lugar de experiências vividas, significantes tanto do sujeito da enunciação estruturando as subjetividades, quanto dos modos de construção cognitiva por um ponto de vista assumido pelo sujeito complexo.

Para a autora, a semiótica, como teoria da significação, fornece uma metodologia para interpretar os componentes da imagem, identificá-los e analisá-los no complexo conjunto da manifestação textual, averiguando como se articulam os sistemas de linguagem do texto, a fim de depreender como se dá a produção de sentido.

A descrição do plano de expressão de uma configuração repousa sobre uma organização sintática e semântica e é, portanto, um estudo tanto do enunciado (que possibilita a caracterização da relação-função das qualidades plásticas dos actantes) quanto da enunciação (que explicita a intencionalidade do arranjo discursivo pelo conjunto de marcas deixadas na manifestação textual da organização, a fim de direcionar o olhar do observador, conduzindo-o a reconstituí-la pelo 
modo como ela se mostra, ou seja, pelo seu regime de visibilidade).

É a partir do inventário dos elementos componentes e da apreensão de sua semiose relacional, portanto, que a descrição da obra centra-se no estudo das comparações e/ou homologações entre as informações do plano de expressão com aquelas que o plano do conteúdo nesse instala. Descrevem-se as categorias semânticas e seus modos de articulação que organizam a unidade entre as partes e o seu todo. "0 resultado é a apreensão do sistema axiológico a partir do qual a obra é construida, assim como dos valores que ela circula e os efeitos de sentido que ela desencadeia na relação estética" (OLIVEIRA, 2004, p. 122).

De acordo com essa abordagem, a construção da significação de um texto obedece ao percurso gerativo do sentido, que vai dos elementos mais abstratos ao mais concretos e pode ser dividido em três etapas: a estrutura fundamental ou profunda, a estrutura intermediária ou narrativa e a estrutura discursiva. Conforme Greimas e Courtés (2011), essas etapas ou níveis são independentes para efeitos de estudo, podendo cada uma delas ser descrita e explicada de forma autônoma, mas cuja relação é condição indispensável para a formação da significação.

A primeira etapa do percurso, a mais simples e abstrata, recebe o nome de nivel fundamental ou das estruturas fundamentais, e nela a significação surge por meio do estabelecimento de uma relação de oposição entre dois termos. Estes, por sua vez, representam duas ideias contrárias, mas de uma mesma categoria semântica. Essa relação é proveniente da redução da rede de relações presentes nos niveis narrativos e discursivos, resultando em termos mais abstratos, sem a especificidade presente naqueles níveis. Graças a essa especificidade, a estrutura fundamental é a última a ser considerada, pois é produto de toda uma construção analítica.

Greimas e Courtés (2011) explicam que em termos operacionais, a oposição mínima do nivel fundamental é representada por meio do quadrado semiótico, uma apresentação visual da articulação de uma categoria semântica, tal como a que pode ser construída, por exemplo, no interior de um universo de discurso dado, categoria que está ali, então, como o coração, o nível mais profundo. "A partir da primeira relação entre os termos opostos, a de contrariedade, se estabelecem outras duas: de contradição e de implicação" (GREIMAS; COURTÉS, 2011, pp. 400-401). As relações mais importantes expressas no quadrado não são as de base, de oposição, mas aquelas que mostram a transformação, a passagem de um termo para outro. Essa complexidade de relações mostra que a semiótica, além do binarismo que Ihe é tanto atribuído é, no mínimo quaternária. Ou seja, dá conta da complexidade da dinâmica dos valores. Para exemplificar, utilizaremos o quadrado de veridicção proposto por Greimas e exposto por Bertrand (Figura 1). Mesmo ele integrando o nivel narrativo sobre o qual discorreremos adiante, proporciona uma panorâmica da constituição de discretização de termos, suas oposições e negações, sendo essas relações as que são previstas nesse procedimento metodológico.

0 quadrado da veridiç̧ão se apresenta como uma combinação dos valores de ser e parecer, e de suas negações: a combinação define os termos de "segunda geração". Assim, quando há coincidência do parecer e do ser num universo de discurso, há "verdade"; a coincidência do parecer e do não-ser define a "mentira"; a do não-parecer e do ser define o "segredo"; enfim, a coincidência do não-parecer e do não-ser define a "falsidade". (BERTRAND, 2003, p. 241 , grifo do autor) 


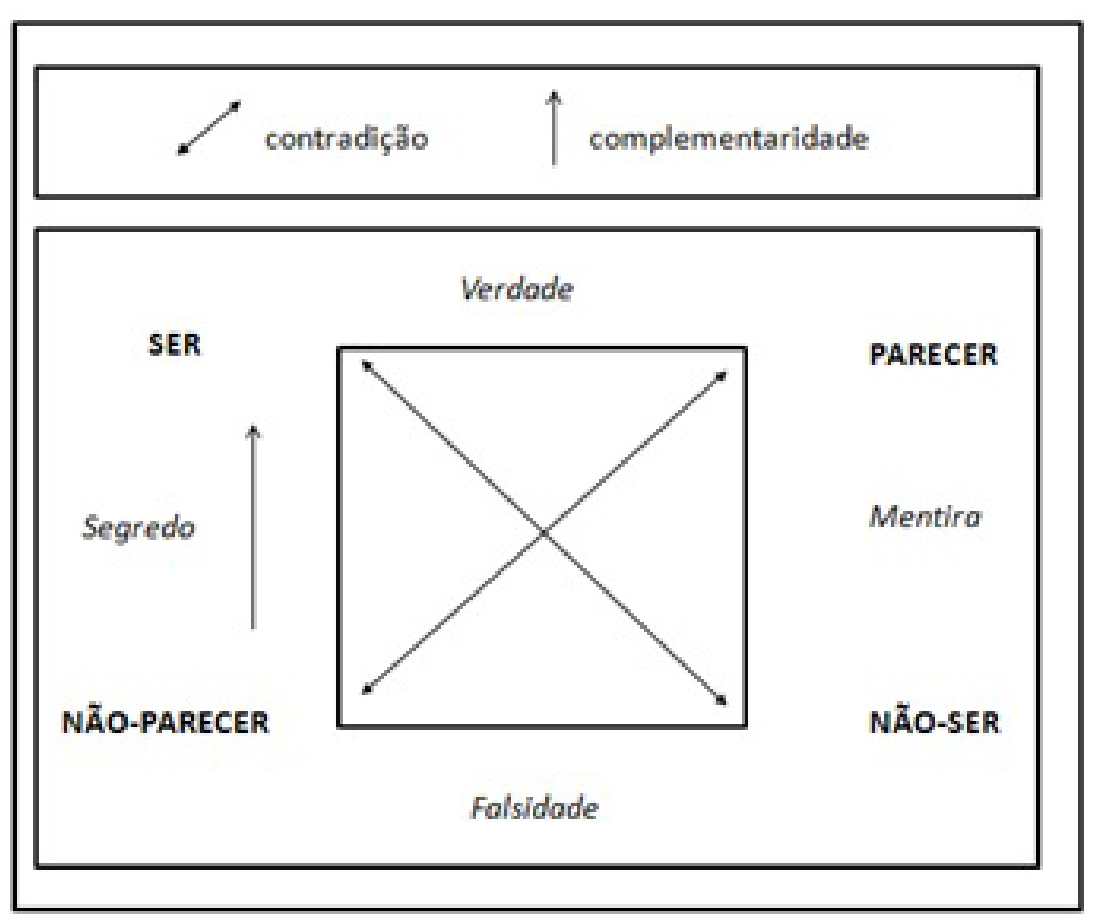

Figura 1 - Percurso gerativo do sentido "o quadro de veridiccção".

Fonte: Bertrand (2003, p. 241).

Na sequência do percurso, a estrutura narrativa apresenta uma sintaxe e uma semântica narrativas. Acontece uma ascensão de um sujeito inscrito na narrativa. Além da presença do sujeito, temos a inscrição de certos valores em objetos com os quais são estabelecidas relações de junção ou de disjunção, sendo a narratividade o componente primordial para a transformação de estados então desencadeados. Sendo assim, a passagem dos valores axiológicos virtuais do nível fundamental para o nível narrativo realiza-se pela inscrição de valores em objetos e a junção/disjunção dos sujeitos com os objetos-valor, previstos em esquemas de manipulação, de competência, da performance e das sanções que podem ser atribuídas ao sujeito da performance.

Quando a narrativa chega até a superfície, temos a passagem para a estrutura discursiva, o nivel mais superficial do percurso gerativo da significação. Segundo Greimas (1976), as estruturas discursivas são as mais especificas, mas também mais complexas e "enriquecidas" semanticamente que as estruturas narrativas e fundamentais.

É no nível discursivo que o enunciador transmite seus sistemas de valores para o enunciatário, por meio da criação de interações em um processo comunicacional, com o objetivo tanto de convencê-lo, persuadi-lo, quanto de com ele partilhar os sentidos.

Os perfumes das casas de alta-costura e prêt-à-porter são analisados dentro do contexto do universo do luxo e da moda. Partindo dessa premissa, nos baseamos na estrutura do percurso gerativo e nos estudos de Ana Claudia de Oliveira sobre as linguagens da moda, mais precisamente na relação entre corpo, moda e construção identitária desenvolvida nos textos "Nas interações corpo e moda, os simulacros" (2007) e "Semiótica e moda: por um estudo da identidade" (2008).

Neles, fundada nos estudos sobre a moda, a semioticista estabelece relações entre modos de presença do sujeito e modos de construção identitária, propondo uma tipologia dos modos do vestir-se em relação aos regimes de presença e visibilidade do sujeito. Ela chega assim, a quatro modos de o sujeito vestir-se, e cada 
um deles ocupa uma posição no quadrado semiótico: nos contrários, o sujeito que se veste para si próprio (subjetal) em oposição ao sujeito que se veste pelos atributos da roupa (objetal); na posição de subcontrário do vestir subjetal, há 0 sujeito que veste a roupa pelos seus fins práticos (pragmático) e, em oposição a esse tipo, no outro eixo dos subcontrários do quadrado semiótico, o sujeito que se veste para obter status por meio da roupa (simbólico). Reproduzimos abaixo a representação visual e esquematização do quadrado (Figura 2):

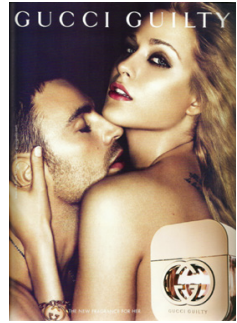

Sujeito perfumado objetal

Parecer para o outro

Visibilidade - querer não ser visto sem perfume (o perfume faz o sujeito)

(notas florais intensas, florais orientais, frutais intensas)

Regime de junção

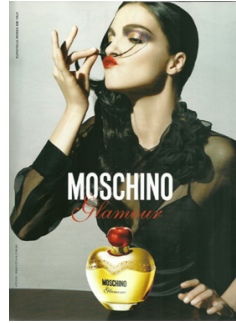

Sujeito perfumado subjetal

Parecer para si

Visibilidade - quer ser visto pela interação do perfume com o corpo (notas florais, sintéticas e frutais)

Regime de união

Sujeito que se perfuma para si

Sujeito que se perfuma pelo perfume

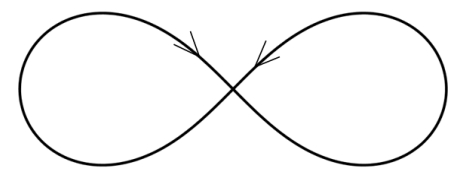

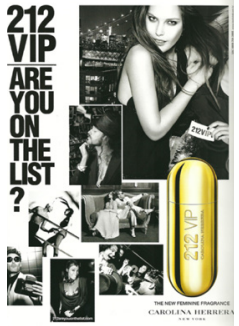

Sujeito perfumado simbólico

Parecer pelo social

Visibilidade - não querer não mostrar o

corpo e o perfume

(notas florais e frutais)

Regime de junção

Sujeito que se perfuma pela visibilidade

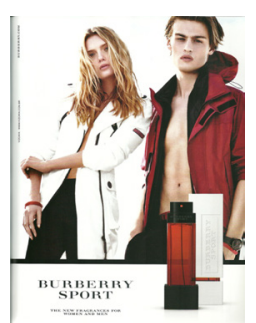

Sujeito perfumado pragmático Parecer pelas atividades

Visibilidade - não quer mostrar o corpo e o perfume (notas aquáticas e ozonizas)

Regime de união

Sujeito que se perfuma com fim prático

Figura 2 - Tipologia dos sujeitos perfumados. Fonte: A autora (2015).

No decorrer do levantamento e do tratamento do corpus, verificamos que as mesmas relações do corpo vestido poderiam ser também apreendidas com 0 corpo perfumado no que tange à construção de uma imagem de si e para o outro. Em decorrência dessa constatação, empregamos a mesma terminologia ao aplicarmos o modelo proposto por Ana Claudia de Oliveira aos sujeitos pressupostos que foram sendo construídos a partir e nas publicidades de perfume analisadas. 
Destacamos que o que difere no modo de apresentação do quadrado semiótico tradicional é a troca das setas, que fazem a indicação da dinâmica do quadrado pela elipse. Optou-se pelo uso da elipse para enfatizar que essas posições são dinâmicas e interagem entre si, conforme a atuação do sujeito.

Os modos de presença dos sujeitos nos anúncios de perfume traçam a construção de simulacros que são adotados por outros sujeitos, projetados no imaginário. Destacamos que enquanto "[...] os simulacros encontram quem os adote, nascem os 'sujeitos' que os assumem" (LANDOWSKI, 1992, p. 172). Essas relações que se dão entre sujeitos ocorrem nos meios midiatizados e, no caso de nossa pesquisa, nos anúncios impressos. Nestes, o enunciatário se projeta na figuratividade das publicidades de perfume das casas de alta-costura e prêt-à-porter, identificando-se e se perfumando como os tipos de sujeitos perfumados propostos.

$\mathrm{Na}$ categoria do corpo perfumado subjetal estão os sujeitos que privilegiam a dimensão estésica ao se perfumar. Eles se perfumam primeiro para si, para se aprazer com os sentidos e com os valores propostos pelo perfume, tendendo a atualizar a esfera do subjetivo. 0 destinador induz o destinatário ao descobrimento de si a partir de arranjos discursivos, nos quais os actantes do enunciado são presentificados em relações que levam à percepção de si, atualizada pelo perfume. Nessa interação, o sujeito se ajusta ao perfume e o perfume se ajusta ao sujeito, levando ao estado de alma da espreita de si mesmo, por si mesmo. Esse modo de construção está vinculado ao universo subjetal, no qual sujeito e perfume colocam-se em uma relação de continuidade; o perfume leva o sujeito ao encontro consigo mesmo, fundado na dimensão sensorial. A vitalidade do corpo é recuperada na vitalidade do perfume, e todas as qualidades de um e de outro são sentidas e significadas pelo próprio sentir o processo estésico. Em regime de união sensorial, um não anula o outro, e o estado patêmico resultante é aquele da espreita de si, por si mesmo. Os tipos de perfumes usados por esse sujeito são de formulação basicamente floral, sintética (aldeídos) e frutal'.

Esses simulacros de sujeitos perfumados são vistos na última página da publicidade de Chanel $N^{0} 5^{2}$, na qual a figura feminina está em um encontro com ela mesma e é atualizada pelo perfume, mostrando-se segura e pronta para atuar no mundo; no anúncio do perfume da marca italiana Moschino, no qual vemos uma mulher que se apraz em sentir, cheirar a si própria e que em última instância cheira todo glamour proporcionado pelo perfume; no anúncio do perfume The One, em que o sujeito experimenta a si mesmo em uma outra dimensão, a memória. São assim sujeitos que descobrem a relação com o sentir a si mesmo pelo perfume, sentem-se e ganham existência pela sua aparência perfumada, seduzindo 0 enunciatário a entrar em conjunção com essas formas de ser única, glamourosa ou segura de si e pronta para agir no mundo.

Em oposição ao corpo perfumado subjetal, que prima pela dimensão estésica, como vimos, encontra-se o corpo perfumado objetal, que, por sua vez, se perfuma pelos atributos oferecidos pelo perfume e sua marca, criando um modo de presença fundado no parecer para o outro. Nessa categoria, o sujeito é dominado e remodelado por aquilo que é proposto pelo perfume. 0 perfume é o objeto de valor e o sujeito é visto a partir de repercussões do estar assim perfumado. A visibilidade do sujeito que se perfuma de forma objetal se dá pelo perfume e 0 estado patêmico causa ações de exibicionismo, o que perfuma o sujeito é o que torna seu atrativo maior. 0 perfume reconstrói o sujeito que se faz ser admirado por sua aparência olfativa, segundo um domínio do parecer positivado no social. $\mathrm{Na}$ perspectiva do corpo perfumado objetal, o sujeito tem por base o predomínio do "parecer" feminina ou sedutora para o outro, em oposição ao sujeito subjetal, para o qual a relação consigo mesmo de "ser" ou se sentir da mesma forma já seria suficiente. 
Temos aqui sujeitos em relação de descontinuidade com sua real aparência olfativa. Eles constroem o parecer pela ação do perfume, e isso pode ser observado na publicidade do perfume J'adore, na qual o perfume torna a mulher absolutamente feminina, cuja construção da aparência olfativa se dá pela ação do cromático que, inclusive, elabora uma significação um tanto literal no anúncio, qual seja, a de que essa mulher feminina nasce do perfume. Na publicidade de Chance, o perfume atualiza a mulher, que se torna impulsiva e aproveita todas as oportunidades, inclusive sexuais. Nos anúncios de Gucci Guilty e Armani Code, 0 perfume revela mulheres como sujeitos irresistíveis, extremamente competentes a seduzir, Gucci é o culpado pela sedução e Armani dá o código secreto que habilita a mulher a tomar atitude e dominar a cena da sedução. Os perfumes que os sujeitos dessa categoria usam primam pelo efeito da intensidade, em formulações de floral intenso, floral oriental e frutal intenso. Nessa categoria, os sujeitos perfumam-se para parecer, apagando qualquer aparência olfativa natural; o perfume pelo perfume esconde o sujeito.

Ocupando a posição de subcontrário, no mesmo eixo do sujeito que se perfuma para si ou subjetal, está o sujeito que se perfuma com fins práticos. Nessa categoria, estão os corpos perfumados que concretizam a posição da dimensão pragmática. 0 perfume cumpre o seu papel de instrumento de proteção do corpo no que diz respeito a "não cheirar mal", o que Ihe dá a competência de aventurar-se e ainda assim ter uma aparência olfativa agradável. São sujeitos que buscam a praticidade e a funcionalidade do perfume, solicitadas na performance que mobiliza a competência de não fazer sentir os odores naturais do corpo após a prática esportiva ou ao término do dia. 0 traço da funcionalidade prevalece e instaura-se uma relação de não descontinuidade entre o sujeito e o perfume na medida em que, nela, ainda prevalece a aparência olfativa considerada favorável, mesmo após a realização de várias atividades, e o estado patêmico é o do corpo sentir-se à vontade com a atuação do perfume. A adjetivação de funcionalidade desse tipo de perfume é produzida principalmente pelos modos como se dá a sua formulação: são perfumes com notas aquáticas, ozônicas e refrescantes. Nas publicidades de Chrome Sport e Burberry Sport, os sujeitos sentem-se habilitados a aproveitar toda a esportividade proporcionada pelo perfume, seja no ar ou no mar.

Em oposição ao sujeito que se perfuma de forma prática, no outro eixo dos subcontrários do quadrado semiótico está o perfumar-se em busca de status ou posição social de visibilidade. Nessa categoria, encontram-se os sujeitos que se perfumam com fim simbólico. 0 perfume valoriza o sujeito, que se conforma ao simbolismo que esse lhe transfere. A aparência perfumada impera sobre a aparência do seu corpo, e é o perfume que faz o sujeito ser para o outro e para si mesmo subjugado pelo simbólico. 0 estado patêmico é o de recobrir-se com o valor simbólico para mascarar-se com esses atributos de beleza, inclusão social, riqueza, entre outros, e ter o valor e status assegurado. 0 enunciador dá a ver esses sujeitos em arranjos discursivos de destaque no meio midiático, em modos de presença valorados positivamente no universo da moda e euforizados no espaço social. 0 perfume proporciona inserção social, colocando os sujeitos na modalidade do querer ser visto por sua aparência olfativa, em consonância com os valores eleitos pelo social.

Nessa categoria, podem ser verificadas publicidades de perfumes com uma formulação de base floral ou frutal. Na maioria dos casos, a própria nomeação do perfume orienta para uma leitura simbólica do próprio, dá a ver a condição simbólica de instituir visibilidade aos sujeitos, como, por exemplo, o perfume 212 VIP, cuja promessa é inserir o usuário em um mundo de valores de exclusividade e destaque voltado a poucos "afortunados" ou Very Important Person. Outros exemplos podem ver verificados no anúncio de Lady Million, no qual se apreende 
uma mulher em conjunção com os valores de riqueza e poder, assim como em Parisienne, que promete transformar qualquer mulher em "uma parisiense". Por último, a publicidade de Infusion D'Iris dá a ver um sujeito em harmonia com os valores de tradição e sofisticação da marca Prada.

As proposições para um fazer fazer e um fazer ser estão concretizadas nas relações e inter-relações do fazer ver, investidas na dimensão enunciativa das publicidades de perfume das casas de alta-costura e prêt-à-porter, que, por extensão, são também anúncios de moda, cujos usos são definidos por Ana Claudia de Oliveira da seguinte maneira:

[...] a coagir o destinatário a se arrumar segundo padrões que transformam essas figuras vestidas em veículos prescritivos investidos da promessa de conferir àquela que os adota a sua aceitação social, uma vez que, vestida como ditam que se deve estar, a pessoa mesma proclama o seu pertencimento ao meio. Assim é que o sujeito, tem um amplo leque de criação da sua aparência, igualmente, ele se encontra cerceado pelos modelos que Ihe possibilitam um número reduzido de modos de mostrar-se.

Desde seu início, a mídia vai se organizar de forma a dar legitimidade às fórmulas verbo-visuais que põe em circulação. Como a moda ela faz fazer como todo mundo. Moda é imposição de comportamentos e usos por mecanismo coercitivos, que funcionam dissimulados nos mecanismos de desejo de pertencimento, de inclusão no grupo, que movem a volição do destinatário numa orientação definida. (OLIVEIRA, 2007, p. 19)

Sendo assim, o que a moda faz ver e faz fazer são modos de se vestir, de acordo com Oliveira, e aqui, no caso dos anúncios estudados, são modos de se perfumar. Ela, a moda, também faz ser nos modos de se perfumar e de mostrar-se perfumado, de um sujeito ao outro. Nessa relação intersubjetiva (o sujeito que se mostra e que vê), coexistem os objetos do cotidiano dos sujeitos, sendo um deles o próprio corpo, o corpo como suporte de sentidos e de valores objetivados e subjetivados no e pelo perfume que o veste, que o reveste, que o transveste, etc. Corpo e perfume se dão a ver nas publicidades como produtores de efeitos de sentido, na medida em que interagem na construção do sujeito perfumado e como estratégias de convocação do enunciatário dos anúncios.

Os anúncios publicitários de perfume figurativizam corpos desejantes e desejáveis, e, diante de tais sujeitos, o enunciatário, é presentificado. Nessa intrincada estratégia enunciativa se estabelece uma rede de significações e, principalmente pelo jogo de olhares, o consumidor é convocado a participar da conversa. Landowski (1992) afirma que nesses jogos ópticos o destinador coloca-se na posição de querer ser visto e os destinatários, sujeitos autônomos, de acordo com a sua intenção volitiva podem querer ver, querer não ver, não querer não ver, não querer ver. Embora em nossa pesquisa acreditemos que, quando o destinatário se põe a folhear a revista, ele está predisposto a querer ver.

0 enunciador, fazendo uso de diferentes recursos, vai trabalhando os regimes de visibilidade dos sujeitos na publicidade. Nas relações entre eles, "será o sujeito virtualmente observável que, procurando ele próprio, de certa forma 'fazer-se ver', organizará o dispositivo requerido para a 'captação do olhar' de um observador potencial" (LANDOWSKI, 1992, p. 89). Dando sequência a esse conceito, o semioticista afirma que pelo simples fato de existirem, as pessoas passam a ser sujeitos visíveis. Edificam relações além do ver e ser visto, mas também relações intencionais como fazer ver e fazer ser visto, sendo que o sujeito que vê não é um simples receptor, mas um captador de imagens, que recebe o papel de sujeito operador. 
A maneira com que esses sujeitos se perfumam está ligada à sua forma de visibilidade e trânsito no mundo: o sujeito que se perfuma de forma subjetal dá-se a ver para si, enquanto o que se perfuma de forma objetal instaura uma visibilidade para o outro. Já aquele que se perfuma de forma prática, o sujeito perfumado pragmático, dá-se a ver por sua atividade, e o que se perfuma simbolicamente dá-se a ver pelo social.

Cunhado por Landowski, o regime de visibilidade norteia as relações entre o público e o privado, que se subordinam à "sintaxe do ver" e às relações de reciprocidade entre "um que vê" e "outro que é visto".

\begin{abstract}
Uma vez colocada como necessária e suficiente, a relação mínima constitutiva do ver admite, em níveis mais superficiais, diferentes especificações modais (essencialmente do tipo querer, dever, saber, poder ver), cujo emprego condiciona a maneira como os actantes, no caso os dois agentes - individuais ou coletivos - designados como o que "vê" e o que "é visto", entram em relação. [...] em particular quando [...] necessário atribuir um lugar aos dispositivos de "iluminação" (que "permitem ver") e aos procedimentos de "captação" (que "garantem ser visto"). (LANDOWSKI, 1992, p. 90)
\end{abstract}

A publicidade constrói, ressignifica e desnuda determinados papéis sociais colocados de maneira eufórica no anúncio, buscando criar uma identificação com o leitor que irá interferir diretamente na construção de sua identidade, com vistas ao modo de visibilidade dos sujeitos projetados no anúncio. Em seus estudos sobre os anúncios publicitários da beleza feminina, Landowski afirma que as imagens constituem, no tocante, ao seu modo de exposição ao público, um conjunto homogêneo, e que "a maneira como estes elementos são figurados, o modo como eles são utilizados para fazer valer uma marca ou um produto, não é neutro" (LANDOWSKI, 2002, p. 125). Essas imagens traduzem uma visão determinada dos papéis sociais ligados a valores.

A partir do quadrado, podemos depreender os modos de presença do sujeito articulados pela sua forma de se perfumar. Pelo perfume, o sujeito constrói modos de visibilidade diferenciados que dão a ver gostos, estilos de vida e modos de se posicionar no social que irão originar modelos ou simulacros de identidade ou alteridade.

\title{
Considerações finais
}

Ao se perfumar de forma subjetal, objetal, prática (pragmática) ou simbólica, o corpo perfumado opera o fazer ser o sujeito perfumado a partir de sua aparência olfativa, construída tanto pela fragrância quanto pelo universo de valores propalado pela marca do perfume. Esses sujeitos podem, assim, assumir uma multiplicidade de estados ou enfatizar um deles pela sua força estética ou estésica, dada pelo que o corpo perfumado pode sentir de si mesmo, pela sua força funcional ou pela sua força simbólica, em mecanismos de construção identitária. Com esses quatro tipos diferentes de articulação entre o corpo e o perfume, objetivamos estabelecer como se processa identitariamente o sujeito perfumado. As quatro posições da quadratura são operacionais na descrição do papel do perfume no perfumar o corpo, na mítica do ser perfumado e em seus papéis na construção identitária.

Em cada posição do quadrado pode-se depreender a visibilidade do sujeito pelas suas articulações entre corpo e perfume, que configuram o sujeito perfumado, e the conferem modos de presença distintos no mundo. As formas de inter-semiotização entre corpo e perfume - e consequentemente às marcas de alta-costura e 
prêt-à-porter, que estão diretamente ligadas à moda e ao mercado do luxo - autorizam uma abordagem dos modos de presença do sujeito perfumado nas práticas sociais com a exposição de seus fazeres e seus papéis na construção identitária. Do ponto de vista dos modos de interação entre corpo e o perfume, e de como esses modos participam dos relacionamentos entre os sujeitos em dado espaço e tempo, podemos depreender os modos de ser e estar no social do ser perfumado.

A diversidade de simulacros de aparências perfumadas institui diferentes formas de consumo que levam a uma necessidade de construção de estratégias de convencimento do consumidor por parte das marcas a partir das publicidades. Essas estratégias são articuladas de forma sofisticada e configuradas em tipos de relações interativas que levam o sujeito a querer estar em conjunção com os valores propalados pelo perfume e pela marca.

Nas publicidades de perfumes estudadas, apreendemos que a construção dos valores (e dos sentidos) se dá por e através do perfume e da marca, que busca despertar o desejo em seus consumidores-enunciatários com programas narrativos que permitem fazer ser o sentido a partir da construção mútua, ajustada entre eles. A adoção do perfume é um dos atributos qualificantes do sujeito e de sua cultura, pois o arranjo do corpo perfumado, adotado pelo sujeito como uma estrutura de linguagem do seu interagir social, explicita que ele é moldado para exercer o papel de exclusividade e importância propalado pela marca. 0 efeito de sentido de luxo e exclusividade é edificado pelo fazer do perfume que influencia a ação dos sujeitos.

0 sujeito perfumado sente com os seus sentidos a ação do perfume em sua pele. As notas, mesmo que apenas figurativizadas no papel, evaporam e se fazem sentir criando os efeitos de sentido anunciados. No desenvolvimento dessa ação significante, o sujeito sente o perfume e sente a si mesmo, em um processo estésico, proveniente do ato de sentir o corpo perfumado em funcionamento. A construção identitária dá-se pelo ato do sujeito sensivelmente sentir o agir do perfume nos simulacros de sujeitos sedutores, aventureiros, poderosos, ricos, vips, glamourosos ali presentificados.

Esses simulacros instituem também um fazer sentir que se dá na perspectiva do ajustamento. 0 fazer saber a fragrância com as notas presentificadas no perfume caminha junto com um fazer sentir mobilizando uma competência estésica do sujeito na apreensão do sentido. Os simulacros instaurados passam então da ordem do visivel para a ordem da experienciação; o sujeito é levado a sentir 0 que o outro sente, entrando em união como os tipos de sujeitos perfumados e os estilos de vida propostos pelas marcas. Os simulacros de seres perfumados são erigidos como desejáveis a partir de critérios estéticos instituídos pela moda e pela mídia. A aceitação ou não desse modo de presença dependerá da apreensão ou não pelo enunciatário das qualidades do perfume. Assim, a performance proposta pelo enunciador, no programa narrativo de entrar em conjunção com o modo de ser do sujeito perfumado, passa pela ordem cognitiva, dada pelo reconhecer as qualidades atribuídas ao perfume como desejáveis, em paralelo à performance sensivel ligada ao prazer estésico que esse ser perfumado leva o outro a sentir. 


\section{NOTAS}

Os perfumes são agrupados em sete famílias olfativas utilizando a nomenclatura original francesa Hespéridée (ou cítrico, tem como principal caracteristica o fresco), Florale (formulações complexas, junta-se várias flores, atualmente, a família floral representa cerca de $60 \%$ a $65 \%$ dos perfumes vendidos), Fougère (combinação de aromáticos, musgo e madeiras, com notas de lavanda e cumarina e nuances doces de fava tonka. Usados principalmente em perfumes masculinos). Chypre (base de perfumes sofisticados; o nome vem de um perfume homônimo que François Coty lançou em 1917), Boisée (ou amadeirada, é a familia na qual se encontram notas de caráter quente e opulento), Ambrée (ou oriental, notas descritas como sofisticadas, quentes e sensuais, trazendo perfumes com intensa fixação e longa duração) e Cuir (ou couro, é uma com formulação bastante diferente, com notas secas que tentam reproduzir o odor caracteristico do couro (fumaça, madeira queimada, tabaco e bétula).

${ }^{2}$ As publicidades citadas, e que não estão visiveis no quadrado acima, fazem parte da pesquisa de doutorado composta por 142 anúncios de perfumes das casas de alta-costura e prêt-à-porter veiculados na Vogue Brasil de 2010 a 2014. Os anúncios citados no texto podem ser visualizados em: <https://br.pinterest.com/taisavieira13/ an\%C3\%BAncios-de-perfume-doutorado/>.

\section{REFERÊNCIAS}

BERTRAND, Denis. Caminhos da semiótica literária. Bauru: EDUSC, 2003.

CASTILHO, Kathia; MARTINS, Marcelo M. Discursos da Moda: semiótica, design e corpo. Coleção Moda \& Comunicação. São Paulo: Anhembi Morumbi, 2005.

FLOCH, Jean-Marie. Petite mythologie de l'oeil et l'esprit. Paris: Hades-Benjamin, 1985.

GREIMAS, A. J. Semiótica e ciências sociais. São Paulo: Cultrix, 1976.

GREIMAS, A. J.; COURTÉS, Joseph. Semiótica: diccionario razonado de la teoría del lenguaje. Tomo II. Trad. Enrique Ballón Aguirre. Madrid: Editorial Gredos, 1989.

. Dicionário de Semiótica. Tradução Alceu Dias Lima, Diana Luz Pessoa de Barros, Eduardo Peñuela Canizal, Edward Lopes, Ignacio Assis da Silva, Maria José Castagnetti Sombra, Tieko Yamaguchi Miyazaki. 2. ed. São Paulo: Contexto, 2011.

LANDOWSKI, Eric. A sociedade refletida: ensaios de sociossemiótica. São Paulo/Campinas: EDUC/Pontes, 1992.

. Presenças do outro. Tradução de Mary Amazonas Leite de Barros. São Paulo: Perspectiva, 2002.

. Aquém ou além das estratégias, a presença contagiosa. São Paulo: Edições CPS, 2005.

. 0 triângulo emocional do discurso publicitário. Comunicação midiática, Bauru, n. 6. 2006

. Interações arriscadas. São Paulo: Estação das Letras e Cores, 2014.

MIRANDA, Ana Paula. Consumo de moda: a relação pessoa-objeto. São Paulo: Estação das Letras e Cores, 2008.

OLIVEIRA, Ana Claudia Mei Alves de. Vitrinas: acidentes estéticos na cotidianidade. São Paulo: Educ, 1997.

. Nas interações corpo e moda, os simulacros. In: Caderno de discussão do Centro de Pesquisas Sociossemióticas, São Paulo, vol. 1, n. 13, pp. 17-54, nov. 2007, CD-ROM.

. Nas interações corpo e moda, os discursos da aparência. In: Caderno de Discussão do Centro de Pesquisas Sociossemióticas, São Paulo, vol. 1, n. 14, pp. 1-43, nov. 2008, CD-ROM.

Estesia e experiência do sentido. In: Revista CASA - Cadernos de Semiótica Aplicada, vol. 8, n. 2 . dez. 2010. Disponível em: <http://seer.fclar.unesp.br/casa/article/view/3376/3099>. Acesso em: 4 jun. 2012. 